\title{
Avanafil - A further step to tailoring patient needs and expectations
}

\section{Luca Boeri, Paolo Capogrosso, Eugenio Ventimiglia, Alessandro Serino, Giovanni La Croce, Andrea Russo, Rocco Damiano, Francesco Montorsi \& Andrea Salonia}

To cite this article: Luca Boeri, Paolo Capogrosso, Eugenio Ventimiglia, Alessandro Serino, Giovanni La Croce, Andrea Russo, Rocco Damiano, Francesco Montorsi \& Andrea Salonia (2016): Avanafil - A further step to tailoring patient needs and expectations, Expert Review of Clinical Pharmacology, DOI: 10.1080/17512433.2016.1195261

To link to this article: http://dx.doi.org/10.1080/17512433.2016.1195261

Accepted author version posted online: 27

May 2016.

Published online: 27 May 2016.

Submit your article to this journal $\llbracket$

Џll Article views: 5

Q View related articles $\square$

View Crossmark data ¿ 
Publisher: Taylor \& Francis

Journal: Expert Review of Clinical Pharmacology

DOI: $10.1080 / 17512433.2016 .1195261$

\section{Review}

\section{Avanafil - A further step to tailoring patient needs and expectations}

Luca Boeri, Division of Experimental Oncology/Unit of Urology, URI, IRCCS Ospedale San Raffaele; Via Olgettina 60, 20132 Milan, Italy. Tel. +390226435506; Fax +390226437298; Email: luca.boeri@hotmail.it

Paolo Capogrosso, Università Vita-Salute San Raffaele; Division of Experimental Oncology/Unit of Urology, URI, IRCCS Ospedale San Raffaele; Via Olgettina 60, 20132 Milan, Italy. Tel. +390226435506; Fax +39 02 26437298; Email: paolo.capogrosso@ gmail.com

Eugenio Ventimiglia, Università Vita-Salute San Raffaele; Division of Experimental Oncology/Unit of Urology, URI, IRCCS Ospedale San Raffaele; Via Olgettina 60, 20132 Milan, Italy. Tel. +390226435506; Fax +390226437298; Email: eugenio.ventimiglia@ gmail.com

Alessandro Serino, Division of Experimental Oncology/Unit of Urology, URI, IRCCS Ospedale San Raffaele; Via Olgettina 60, 20132 Milan, Italy. Tel. +390226435506; Fax +39 0226437298; Email: alessandroserino@ hotmail.it

Giovanni La Croce, Università Vita-Salute San Raffaele; Division of Experimental Oncology/Unit of Urology, URI, IRCCS Ospedale San Raffaele; Via Olgettina 60, 20132 Milan, Italy. Tel. +390226435506; Fax +390226437298; Email: giovanni.lacroce@gmail.com

Andrea Russo, Università Vita-Salute San Raffaele; Division of Experimental Oncology/Unit of Urology, URI, IRCCS Ospedale San Raffaele; Via Olgettina 60, 20132 Milan, Italy. Tel. +390226435506; Fax +390226437298; Email: russo.andrea@ hsr.it

Rocco Damiano, Research Doctorate Program in Urology, Magna Graecia University, Loc. Germaneto, 88100 Catanzaro, Italy. Tel. +3909613694001; Fax +3909613696108; Email: damiano@unicz.it

Francesco Montorsi, Università Vita-Salute San Raffaele; Division of Experimental Oncology/Unit of Urology, URI, IRCCS Ospedale San Raffaele Via Olgettina 60, 20132 Milan, Italy. Tel. +390226437286; Fax +390226437298; Email: francesco.montorsi@ hsr.it

Andrea Salonia, Università Vita-Salute San Raffaele; Division of Experimental Oncology/Unit of Urology, URI, IRCCS Ospedale San Raffaele; Via Olgettina 60, 20132 Milan, Italy. Tel. +390226435506; Fax +390226437298; Email: salonia.andrea@ hsr.it

\section{CORRESPONDING AUTHOR}

\section{Andrea Salonia}

Università Vita-Salute San Raffaele

Division of Experimental Oncology/Unit of Urology, URI-Urological Research Institute

IRCCS Ospedale San Raffaele

Via Olgettina 60, 20132 Milan, Italy 
Tel. +3902 26435506; Fax +3902 26437298

Email: salonia.andrea@hsr.it

\section{Abstract}

Introduction: Phosphodiesterase type 5 inhibitors (PDE5Is) represent the first-line treatment for erectile dysfunction (ED). Almost one in two patients, however, show some level of treatment dissatisfaction and up to $30 \%$ fail to respond to any of the currently available PDE5Is. Recently, the second-generation PDE5I avanafil was launched for the treatment of ED.

Areas covered: Pivotal studies of clinical development along with placebo-controlled randomized clinical trials (RCTs) of avanafil in patients with ED were reviewed. Studies concerning the pharmacokinetics and pharmacodynamic of the drug were also analysed. A systematic literature search for English-language studies published up to May 2016 using the Medline database was performed. The search included the terms avanafil and ED.

Expert Commentary: Avanafil is a potent, highly selective PDE5I whose efficacy is comparable to that of currently available PDE5Is in both naïve and previous PDE5I users. Avanafil is effective within approximately 15 minutes of dosing, thus representing the only PDE5I approved for asneeded use, 15 to 30 minutes before sexual activity. Avanafil has high selectivity for the PDE5 isoenzyme, thus resulting in a lower incidence of drug-related side effects compared to other PDE5Is.

Key Words: Erectile dysfunction; therapy; phosphodiesterase type 5 inhibitors; avanafil, selectivity 


\section{Introduction}

Erectile dysfunction (ED) is defined as the persistent inability to attain and maintain an erection sufficient to permit satisfactory sexual performance [1]. ED may affect male physical and psychological health and also have a significant impact on the quality of life of sufferers and their partners [2]. The prevalence of ED varies greatly worldwide, mostly due to variability in the definition of ED used in epidemiological studies [3]. The prevalence of ED increases with age, ranging between $2 \%$ to $15 \%$ in men $40-49$ years of age and $20 \%$ to $40 \%$ in men aged $60-69$ years [3]. All reports show prevalence rates of $50 \%$ to $100 \%$ for men in their $70 \mathrm{~s}$ and $80 \mathrm{~s}$ [3]. However, recent naturalistic observations have shown that one in four men seeking medical attention for the first time for ED in the real-life setting are younger than 40 [4]. Furthermore, despite advances in ED treatment and a widespread awareness of this condition, ED still remains a significantly underdiagnosed and undertreated health condition [5].

Most internationally-agreed therapeutic recommendations outline the importance of a three-step treatment approach to ED [2,6]. In this context, the primary goal of daily clinical practice for ED management is to determine the aetiology of the disorder, which should be either removed or adequately treated wheneyer possible. Indeed, ED may be associated with modifiable or reversible risk factors including lifestyle or drug-related factors that can be either modified before the beginning of any specific treatment [6] or in combination with a dedicated therapy [1,5]. Likewise, comorbid conditions, which may be pathophysiologically linked to ED, deserve adequate treatment, even when non-reversible [2,6,7]. Of importance, sexual dysfunction has been associated with several endocrine disorders (e.g. late onset hypogonadism and hyperprolactinemia) that should be carefully investigated to achieve a better clinical understanding of the patient and, when appropriate, corrected with a targeted pharmacological treatment $[8,9]$.

Phosphodiesterase type 5 inhibitors (PDE5Is) are considered a first-line treatment for ED patients $[2,6]$. Several pre- and post-marketing data are currently available on the safety, tolerability and efficacy of PDE5Is which have been approved by official agencies (i.e. European Medicines 
Agency [EMA] and Food and Drug Administration [FDA]) over the last 15 years. Overall, the response rate for PDE5Is in improving erectile functioning ranges between 60 and 80\% [10-15]. Still, up to $30 \%$ of ED patients fail to respond to any of the currently available PDE5Is [16,17]. Likewise, 30-40\% of initial responders are not satisfied with on-demand treatment even after erectile function recovery [16,17]. Factors associated with either PDE5I non-response or treatment discontinuation include ED severity, incorrect usage, treatment-emergent adverse eyents (TEAEs) along with concerns about the safety profile of the drug, treatment-related lack of sexual spontaneity, and relational or interpersonal factors. Although novel data related to treatment dropoff following Sildenafil's patent expiry have not yet emerged, even cost has been considered a potential reason for drug discontinuation [2,6,15,18-21]. Health-related comorbidities [22,23] and concomitant medications [21,24] are also potential factors for reduced or even absent therapeutic effectiveness, and treatment regime drop-off as well $[2,6,15,19,21]$. Furthermore, almost one in two patients shows some level of treatment dissatisfaction with the currently-available PDE5Is [5] and high rates of drug discontinuation have been reported in clinical practice [20,25].

Overall, the treatment of sexual problems in couples must not be limited to the restoration of erectile functioning, but should aim to enable both partners to enjoy a satisfactory sexual experience [26]. In this context, Hanson-Divers et al. [27] reported that among men with ED the relative importance of success outcomes with regard to their ED treatment were, in order of preference, curing the dysfunction, pleasure, partner satisfaction, reproduction, naturalness, control, duration, spontaneity, penetration and number of sexual encounters per week. As a major point, the temporal association between drug intake and onset of sexual intercourse may also add psychological concerns $[25,28,29]$.

Therefore, in an attempt to better tailor ED treatment, patient preference among individual PDE5Is, and treatment regimens must be clearly considered. Due to the significant number of patients still dissatisfied with currently available therapies, the development of new PDE5Is with enhanced selectivity for PDE5 and specific pharmacokinetics profiles, a faster onset of action, improved oral 
bioavailability and a sufficiently extended duration of drug action is of major clinical importance in the attempt to restore an individual's satisfactory sexual life according to the his own sexual ecology. Avanafil [30] is a highly selective and potent second-generation oral inhibitor of the cyclic guanosine monophosphate (cGMP)-specific PDE5, which was recently approved by the international pharmaceutical regulating agencies in the United States [31] and in Europe [32] for the treatment of men with mild to severe ED [33].

This narrative review aims at giving a practical overview of avanafil as a treatment for ED.

\section{Methods}

To evaluate the available evidence regarding avanafil as a treatment for ED, a literature search for English-language original and review articles either published or e-published up to May 2016 was performed using Google and the National library of Medicine's PubMed database. Keywords included: avanafil; erectile dysfunction. The retrieved articles were gathered and examined. Reference lists of retrieved articles as well as relevant review articles were also studied (Figure 1). The first two sections of the manuscript focus on a critical evaluation of the pharmacokinetics and pharmacodynamics of the drug, mainly to tailor each group of men with the most appropriate treatment. Effectiveness in a broad spectrum ED population was the focus of the third part of the manuscript, principally reporting key aspects/differences between avanafil and other PDE5Is as for published data. Safety and tolerability are the key themes of the last section, with a broad consideration of the specific profile of avanafil in relation to the most commonly reported adverse events. 


\section{Mechanism of action}

\subsection{Molecular Structure}

Avanafil has been characterized as a pyrimidine derivative (chemical name: 4-[(3-chloro-4methoxybenzyl)amino]-2-[2-(hydroxymethyl)-1-pyrrolidinyl]- $N$-(2-pyrimidinylmethyl)-5 pyrimidinecarboxamide;(S)-2-(2-hydroxymethyl-1-pyrrolidinyl)-4-(3-chloro-4 methoxybenzylamino)-5-[(2-pyrimidinylmethyl)carbamoyl $]$ pyrimidine $($ molecular weight $=483.95$ D) which exists as a single enantiomer (= one stereoisomer only with no non-superposable mirror image of itself) with the ability to rotate plane-polarized light to the left (known as Sstereochemistry). The chemical structure of avanafil is different from the standard model of sildenafil, vardenafil and tadalafil. Therefore, avanafil binds to the catalytic site of PDE5 regardless of the spatial orientation of the molecule. This property may significantly increase its affinity for the target enzyme PDE5, thus increasing the clinical efficacy of the drug [34].

\subsection{Pharmacodynamics}

Erection is a complex phenomenon, which implies a delicate and coordinated equilibrium among the neurological, vascular and tissue compartments. Erection includes arterial dilation, trabecular smooth muscle relaxation, and activation of the corporeal veno-occlusive mechanism [35]. Sexual stimulation promotes the release of nitric oxide (NO) from endothelial cells and neurons in the corpus cavernosum, thus increasing GMP levels; cGMP accumulation sets in motion a cascade of events at the intracellular level which causes smooth muscle relaxation and induces a loss of contractile tone of the vessels at the penile level and the consequent filling of blood vessels. The tumescence of the penis leads to the occlusion of the venous vessels that pass into the tunica albuginea, activating the corporeal veno-occlusive mechanism and promoting erection [35,36]. Phosphodiesterases (PDEs) catalyse the hydrolysis of the second messenger cGMP that is involved in signal pathways of cavernous smooth muscle. The mammalian PDE superfamily consists of at least 11 subtypes, located in different concentrations throughout body tissues, mainly in the 
vascular, visceral and pulmonary smooth muscle, with high concentrations of PDE5 in the smooth muscle of the corpora cavernosa of the penis. PDE5 is the most prevalent PDE in the smooth muscle of the corpora cavernosa. Inhibition of PDE5 results in penile erection only when NO is released as a consequence of sexual stimulation [35,37]. As mentioned, avanafil can bind to the catalytic site of PDE5 independently of the spatial orientation of the molecule; this peculiarity may significantly increase the affinity towards PDE5 and, thus, the clinical efficacy of the drug [34,38].

To this regard, the biochemical selectivity of a PDE5I is a key factor in determining its side-effect profile $[39,40]$. The inhibitory activities of avanafil on the various PDE isoenzymes were tested in preclinical studies and compared with those of sildenafil, tadalafil, and vardenafil. Avanafil is a potent competitive PDE5I that produces 50\% inhibition (IC50) of PDE5 at a concentration of 5.2 $\mathrm{nmol} / \mathrm{L}$, as compared with IC50 values of $1.6,0.08$, and $4.0 \mathrm{nmol} / \mathrm{L}$ for sildenafil, vardenafil and tadalafil, respectively [41].

Inhibition of PDE subtypes 1,6 , and 11 is clinically responsible for many of the TEAEs associated with PDE5Is [38,42]. Phosphodiesterase type 6 is located in the retina and is involved in phototransduction; inhibition of the PDE6 isozyme, which controls levels of cGMP in the retina, may cause cyanopsia and other visual disturbances in some patients. Despite their proven excellent tolerability, sildenafil and vardenafil have relatively low PDE5 selectivity compared to PDE6, thus potentially leading to yisual disturbances in up to $6 \%$ of patients $[43,44]$. Conversely, avanafil has a clearly greater relative inhibitory potency for PDE5 than for PDE6 (100-fold), limiting its tendency to cause visual disturbances $[34,38,41,45]$. Phosphodyesterase type 11 is predominantly found in the testis, prostate and striated muscle; its inhibition has been associated with an increase in myalgia and lower back pain. In particular these effects have been associated with the use of tadalafil, whose selectivity for PDE5 is only 25-fold higher than for PDE11 [46,47]. On the contrary, avanafil shows higher selectivity (>19,231-fold) for PDE5 than for PDE11 [38,41] with a consequent low probability of promoting both myalgia and lower back pain. Moreover, avanafil has selectivity which is 10,192-fold greater for PDE5 than for PDE1, which is located in the vasculature and is 
correlated with vasodilatation, tachycardia, and flushing [38,41]. Overall, the high selectivity of avanafil for PDE5 could be clinically translated into a low incidence of TEAEs, making it a molecule with a user-friendly profile, which is convenient for daily clinical practice.

\subsection{Pharmacokinetic Properties}

\subsubsection{Absorption and Distribution}

Avanafil is absorbed quickly upon oral administration [48], with dose-proportional pharmacokinetics in the range of $12.5-600 \mathrm{mg}$ [49], making it particularly appealing for a personalized on-demand use. Single oral doses of avanafil $12.5-800 \mathrm{mg}$ result in a rapid peak plasma concentration (Cmax), with a median time to Cmax (Tmax) of 30-45 min [48] (Table 1). Based on the area under the concentration-time curve (AUC), when avanafil is administered once or twice daily, over a 1- or 2-week period, there is no clinically significant accumulation of the drug [48]. All pivotal studies registering avanafil use in the US and EU and reporting outcomes on efficacy, safety and tolerability, have been performed without any restrictions on alcohol and food intake. Absorption of avanafil from the gastrointestinal tract may be affected by the coadministration of food; a high-fat meal has been demonstrated to reduce the absorption rate with a delay in the time to Tmax of 1.12-1.25 hours, along with a reduction in Cmax ranging between 24 and 39\% after avanafil 100 and $200 \mathrm{mg}$ doses, respectively. However, as a whole, these changes are thought not to be clinically relevant $[32,50]$ (Table 1$)$.

Avanafil is nearly $99 \%$ bound to plasma proteins and has a degree of protein binding that is independent of total drug concentration, age, renal function, and hepatic function [32,50]. Avanafil was not found to accumulate in plasma when dosed $200 \mathrm{mg}$ twice daily over 7 days. Moreover, avanafil was found in semen of healthy volunteers $45-90$ minutes after dosing at $<0.0002 \%$ of the administered dose. The overall effects on spermatogenesis are still unknown [32].

\subsubsection{Metabolism and Elimination}


Avanafil undergoes hepatic metabolism predominantly by the cytochrome P450 (CYP) 3 A4 enzyme and to a minor extent by the CYP2C isoform [32,43]. The main circulating metabolites are M4 and M16 with plasma concentrations of 23\% and 29\% respectively. M4, rather than M16, has shown an in vitro inhibitory capacity on PDE5 that was $18 \%$ of that of avanafil, accounting for nearly $4 \%$ of its pharmacological activity. After being metabolized, $63 \%$ and $21 \%$ of the initial dose of avanafil is excreted in the feces and urine, respectively (Table 1).

\subsubsection{Special Populations}

The pharmacokinetics of avanafil are similar in men aged 18-43 years and in those aged 65-80 years $[32,43,50]$ although few data are available regarding the effects of the drug in men older than 70 years. These findings are not clinically insignificant considering the progressive increase of elderly ED individuals who regularly require a therapeutic aid for daily clinical use. The avanafil pharmacokinetics profile was not clinically affected by hepatic function in patients with mild or moderate hepatic impairment (Child-Pugh class A or B) [32,50] (Table 2). Peak and total exposure to avanafil were lower in men with moderate hepatic impairment $\mathrm{c}$ ompared to men with mildly impaired or normal hepatic function, although the differences were not statistically meaningful [32,50]. There was also no clinically important effect of mild renal impairment (estimated creatinine clearance $\geq 50 \mathrm{~mL} / \mathrm{min}$ but $<80 \mathrm{~mL} / \mathrm{min}$ ) or moderate renal impairment (estimated creatinine clearance $\geq 30 \mathrm{~mL} / \mathrm{min}$ but $<50 \mathrm{~mL} / \mathrm{min}$ ) demonstrated on avanafil pharmacokinetics $[32,50]$. As there are no data available regarding avanafil pharmacokinetic changes in patients with severe hepatic impairment (Child-Pugh class C) or severe renal impairment (estimated creatinine clearance $<30 \mathrm{~mL} / \mathrm{min}$ ), the drug should not be used in these specific populations [32,50] (Table 2).

A single randomized, double blind, crossover study (TA-140) evaluated the QT/QTc interval in healthy men given a 100mg dose or an over-therapeutic $800 \mathrm{mg}$ dose of avanafil. Individuals receiving avanafil 100mg reported no adverse events. An increase in heart rate of more than $10 \mathrm{bpm}$ 
after 1-3 h of avanafil $800 \mathrm{mg}$ was the only adverse event reported. Avanafil seems to have no effect on QT interval when administered at the therapeutic dosage [49].

\subsubsection{Drug interaction}

Avanafil is metabolized by CYP enzymes [32,43]. This allows for possible pharmacokinetic interactions if avanafil is co-administered with other drugs that interact with the CXP system. In healthy volunteers, administration of avanafil $50 \mathrm{mg}$ with a strong CYP3A4 inhibitor (such as ketoconazole $400 \mathrm{mg}$ daily) resulted in a 3-fold increase in the avanafil Cmax and a 14-fold increase in the AUC [32]. Similarly, in healthy volunteers, co-administration of avanafil $50 \mathrm{mg}$ along with another strong CYP3A4 inhibitor, such as ritonavir, led to a 2-fold and 13-fold increase in the avanafil Cmax and AUC, respectively [32]. Thus, avanafil should not be co-administered with strong CYP3A4 inhibitors (Table 2).

Co-administration of avanafil with a moderate CYP3A4 inhibitor (eg, erythromycin) resulted in a 2.0-fold increase in the avanafil Cmax and a 3.0-fold increase in the AUC [32]. Therefore, a reduction in the dose of avanafil should be considered for patients receiving moderate CYP3A4 inhibitors.

Co-administration of avanafil with warfarin produced no clinically important effects of avanafil on clotting indices or on warfarin pharmacokinetic parameters. Likewise, no clinically important pharmacokinetic interactions were observed when avanafil was administered with omeprazole (a CYP2C19 substrate), amlodipine (a CYP3A4 substrate), rosiglitazone (a CYP2C8 substrate), desipramine (a CYP2D6 substrate), or alcohol [32].

Overall, concomitant use of avanafil with agents that reduce systemic blood pressure may result in symptomatic hypotension due to additive effects. As for other PDE5Is, avanafil is known to potentiate the hypotensive effect of nitrates. Therefore, the use of avanafil is contraindicated with nitrates of any form, regardless of whether they are administered intermittently or as a regular treatment [32]. This is of clinical importance despite avanafil having a documented quick onset of 
action and an overall short duration of effect, thus potentially resulting in briefer interactions with drugs of similar mechanisms, such as organic nitrates.

Recent evidence, however, has shown that avanafil, administered with a sublingual dose of nitrates, resulted in smaller changes in systolic blood pressure and heart rate compared to other agents in the same class [51]. In fact, Swearinge et al. [51] reported that both avanafil and sildenafil have no significant effect on blood pressure and heart rate if administered to healthy men $\geq 8$ hours (avanafil) or $\geq 12$ hours (sildenafil) before a sublingual dose of nitrates. However, results may differ in populations with known vascular disease, especially among those using other concurrent pharmacotherapies, as usually happens in the real-life context. In the EU, in the same circumstances, it is recommended that nitrates only be given under close medical supervision [32]. In healthy subjects receiving stable doxazosin or tamsulosin treatment, clinically significant decreases in supine systolic blood pressure have been reported after dosing with avanafil. No syncope or serious adverse events were reported. Therefore, prior to the start of treatment with avanafil, patients should be on a stable dose of alpha1-blockers and should start treatment at the lowest dose of $50 \mathrm{mg}$. Conversely, patients already receiving an optimised dose of avanafil should start alpha1-blocker therapy at the lowest dose [32,49] (Table 2).

Concomitant administration of avanafil and anti-hypertensive drugs (other than alpha-blockers) such as enalapril have resulted in statistically significant decreases in supine diastolic blood pressure [32,49]. Co-administration of avanafil and amlodipine showed no effect on the pharmacokinetics of amlodipine, but maximum and total exposure to avanafil were increased by $28 \%$ and $60 \%$, respectively. Thus, caution is required in the daily practice for patients receiving antihypertensive drugs. 


\section{Clinical evidence}

\subsection{Fast onset effectiveness and great tolerability}

Several studies have assessed the clinical impact of avanafil on different populations of ED patients [50]. There are already five published clinical trials evaluating efficacy, safety and tolerability of avanafil in different clinical settings: four randomized double-blind, placebo-controlled trials, and a fifth trial, which is an open-label extension trial including patients from two of these studies [52-56] (Table 3). These trials share a common study design consisting of a 4-week non-treatment run-in period assessing sexual attempts with a subsequent treatment period of 12 weeks.

Patients were randomized at the end of the run-in period if they had made at least 4 attempts at intercourse during the previous 4 weeks, had an International Index of Erectile Function (IIEF) erectile function domain (IIEF-EF) score of 5-25, and showed a $50 \%$ or greater failure rate in maintaining an erection of sufficient duration to permit successful intercourse. As rigorously defined in previous studies, primary outcome measures were related to 2 questions from the Sexual Encounter Profile (SEP2 is "Were you able to insert your penis into your partner's vagina?" and SEP3 is "Did your erection last long enough for you to have successful intercourse?") and IIEF-EF domain scores.

Goldstein et al. [52] assessed the clinical efficacy and safety of three different doses of avanafil (50mg, 100mg, 200mg) vs. placebo randomly assigned to 646 subjects in a phase III trial. Data analysis showed a significantly greater improvement post-active treatment dosing in SEP question 2 (namely, from $45.4 \%$ to $64.3 \%$; $\mathrm{p}<0.001$; from $46.6 \%$ to $73.9 \%$; $\mathrm{p}<0.0001$; and, from $48.3 \%$ to $77.3 \%, \mathrm{p}<0.0001$ for avanafil 50, 100 and 200mg, respectively). Likewise, avanafil promoted a significant improvement in terms of both SEP3 (namely, from 13.5\% to 41.3\%; $\mathrm{p}<0.001$; from $13.9 \%$ to $57.1 \%$; $<<0.0001$; and, from $12.4 \%$ to $57.0 \%$; $<<0.0001$ for avanafil 50,100 and $200 \mathrm{mg}$, respectively) and IIEF-EF scores (from $12.6 \%$ to $18.1 \%$; $\mathrm{p}<0.01$; from $12.6 \%$ to $20.9 \%$; $\mathrm{p}<0.0001$; and, from $12.8 \%$ to $22.2 \%$; $\mathrm{p}<0.0001$ for avanafil 50,100 and $200 \mathrm{mg}$, respectively) compared to 
placebo. Overall, avanafil 100mg and 200mg promoted greater improvement for patients for all items as compared with avanafil 50mg dose (all $\mathrm{p} \leq 0.001$ ). An additional analysis was conducted to determine the proportion of men who reached a normalized IIEF-EF domain score $(\geq 26)$ after treatment, as stratified by baseline ED severity. Results showed that the rates of individuals with IIEF-EF $\geq 26$ were greater with all doses of avanafil than with placebo, regardless of baseline ED severity.

The phase III REVIVE study, conducted by Goldstein et al. [53], prospectively assessed in a double-blind, placebo-controlled fashion, the efficacy of avanafil in 390 diabetic men randomized to receive the study medication (either 100 or $200 \mathrm{mg}$ ) or placebo 30 minutes prior to sexual intercourse for 12 consecutive weeks. Results showed that both avanafil doses met the primary endpoints compared to placebo regardless of the type of diabetes, duration of diabetes, severity and duration of ED. More precisely, SEP2 (from $32.5 \%$ to $54.0 \%$ and from $41.5 \%$ to $63.5 \%$; $\mathrm{p}<0.001$ for avanafil 100 and $200 \mathrm{mg}$ doses, respectively), SEP3 (from $8.2 \%$ to $34.4 \%$ and from $8.0 \%$ to $40.0 \% ; \mathrm{p}<0.001$ for the two doses, respectively) and IIEF-EF scores (from $11.2 \%$ to $15.8 \%$ and from $12.0 \%$ to $17.3 \%$; $<<0.01$ for avanafil 100 and $\mathrm{p}<0.001$ for avanafil $200 \mathrm{mg}$, respectively) significantly improved after avanafil treatment.

In a phase III study Mulhall et al. [55] evaluated the effects of avanafil in a cohort of men following surgery for prostate cancer. They enrolled 298 patients who had undergone bilateral nerve-sparing radical prostatectomy for localized prostate cancer $\geq 6$ months prior to screening and had a selfreported normal potency before the diagnosis of prostate cancer. At baseline, and prior to study enrolment, $71.5 \%$ of patients complained of severe ED. Patients were then randomized to receive avanafil $100 \mathrm{mg}, 200 \mathrm{mg}$ or placebo for 12 consecutive weeks. The drug was taken approximately 30 minutes before the initiation of sexual activity. Moreover, patients were restricted to a maximum of two doses per 24-hour period. At the trial's end there were significantly greater increases in SEP2 (from $17 \%$ to $32 \%$, and from $20 \%$ to $41 \%$, with the $100 \mathrm{mg}$ and $200 \mathrm{mg}$ doses, respectively) and SEP3 (from 5\% to $23 \%$, and from $5 \%$ to $26 \%$, with the $100 \mathrm{mg}$ and $200 \mathrm{mg}$ doses, respectively), and 
significantly greater changes in the mean IIEF-EF domain (40\% and 55\% change, with the two doses, respectively) with avanafil (both doses) vs. placebo $(\mathrm{p}<0.01)$. Of importance, both doses of avanafil produced significant improvements in EF regardless of baseline ED severity and patient age. The study medication was well tolerated without significant TEAEs.

Despite the fact that the pharmacological profile of avanafil suggests some advantages, head-tohead comparative studies among currently available PDE5Is are lacking. Yuan et al. [15], in a comparative network meta-analysis of RCTs on PDE5Is, concluded that tadalafil could be the most effective PDE5I for ED treatment, followed by vardenafil. Chen et al. [57], in a recent network meta-analysis considering four outcomes (SEP2, SEP3, GAQ1 and normalization of IIEF-EF score), concluded that patients who wish to prioritize the efficacy of PDE5Is should receive sildenafil $50 \mathrm{mg}$ as the treatment of choice. Otherwise, men who wish to optimize tolerability should take tadalafil $10 \mathrm{mg}$. More recently, Corona et al. [58] performed a comprehensive review and meta-analysis of the placebo-controlled RCTs on the effect of avanafil in the treatment of ED and found that avanafil had comparable efficacy, but lower incidence of drug-related side effects, compared to first-generation PDE5Is. More specifically, avanafil led to significant clinical improvements in all of the considered efficacy outcomes. Avanafil $100 \mathrm{mg}$ and $200 \mathrm{mg}$ were significantly superior to placebo in improving SEP3, independently of ED severity, ED duration and associated morbidities. Of clinical importance, avanafil $100 \mathrm{mg}$ was less effective in older individuals, but this was not the case for avanafil $200 \mathrm{mg}$ prn. Similar rates of avanafil's superior efficacy over placebo were also reported for SEP2 and IIEF-EF. In addition, avanafil use resulted in a 3 -fold increased probability to normalize EF compared to placebo. Of note, comparing only the highest dosage for all worldwide currently-available PDE5Is, no significant differences in efficacy were observed [57,58].

\subsection{Timing matters}

Treatment of ED in men affects both the physiological and psychosocial components of sexual functioning, thus including emotional and sexual intimacy in the couple and sexual self-confidence 
in the male. Data from the literature clearly demonstrate that greater spontaneity, sexual selfconfidence and time concerns associated with PDE5I therapy may hold influence over treatment preference and compliance $[28,29,59,60]$. Therefore, rapid onset of action of PDE5Is is of key importance for convenience and to provide patients with adequate confidence to initiate sexual activity without worrying in terms of post-dosing delay before its onset of action $[28,29]$.

In their phase III trial, Goldstein et al. [52] analysed the efficacy of avanafil at different time intervals of drug intake and found a total number of 300 sexual attempts within 15 minutes of dosing resulting in $64 \%, 67 \%$ and $71 \%$ successful attempts with avanafil 50mg, 100mg, and 200mg, respectively, as compared with $27 \%$ with placebo. The 52-week phase III open-label extension of the same study and of the Research Evaluating an Investigational Medication for Erectile Dysfunction (REVIVE) trial, including a total number of 712 men with and without diabetes treated with $100 \mathrm{mg}$ avanafil with the option to uptitrate to $200 \mathrm{mg}$ for efficacy, or to decrease to $50 \mathrm{mg}$ for tolerability, showed that SEP3 was achieved by $83 \%$ of patients within 15 minutes and in $74 \%$ of patients attempting sexual intercourse after 6 hours [53]. Similar data were published by Hellstrom et al. [61] in a single-blind randomized phase II trial comparing avanafil (namely, avanafil 50mg, $100 \mathrm{mg}$ and $200 \mathrm{mg}$ doses) vs. sildenafil (50mg) or placebo in terms of efficacy, safety and time course in 82 patients. The authors objectively assessed EF with RigiScan monitoring to determine the duration of and time to $\geq 60 \%$ penile rigidity, maximum rigidity, tumescent activity units, rigidity activity units, and responses to the five-point Erection Assessment Scale. They showed that peak response with avanafil occurred within 20 to 40 minutes after all dosing (50-200mg) vs. 60 to 80 minutes for sildenafil 50mg [61]. Moreover, in the 20-40 minute time frame, avanafil $200 \mathrm{mg}$ was clearly superior to sildenafil $50 \mathrm{mg}$ treatment for duration of $>60 \%$ rigidity for both the tip and the base of the penis $(\mathrm{p}<0.05)[61]$.

More recently, Hellstrom et al. [62] conducted a multicentre randomized, double-blind, placebocontrolled phase-IV trial to assess the approximate 15 minute post-dosing effect of either avanafil $100 \mathrm{mg}$ or $200 \mathrm{mg}$ taken as an on-demand treatment for mild to severe ED compared to placebo. 
Patients were mostly Caucasian, non-diabetic adults who had suffered from ED of varying severity (from mild to severe) for at least 60 consecutive months. All men were issued a stopwatch to facilitate time-keeping and were encouraged to attempt intercourse approximately 15 minutes postdosing. Specifically, patients were instructed to start the stopwatch upon taking the study drug, stop the stopwatch once they achieved an erection sufficient for vaginal penetration, and record the time and their responses to specific questions about the sexual experience in a diary. The primary end point of the study was the per-subject proportion of sexual attempts that resulted in both satisfactory completion of sexual intercourse (SEP3) and vaginal penetration within approximately 15 minutes of dosing. To provide a frame of reference for objectively interpreting whether a sexual attempt was effectively successful at approximately 15 minutes post dosing, patients were required to have a positive response to both diary question 5, regarding their ability to maintain an erection sufficient for completion of sexual intercourse (SEP3), and a stopwatch time of no longer than 17 minutes and 59 seconds. Additional end points included the percentage of positive SEP2 questions, percentage of successful sexual attempts at maintaining erection and completing successful intercourse (SEP3), and change in the EF domain of the IIEF, The analyses were performed in the intent-to-treat (ITT) population and included 414 patients who were randomly assigned to treatment $(94.1 \%$ of 440 individuals), took 1 or more dose(s) of the study drug, and had at least 1 post-dose efficacy assessment. The 'evaluable population' included $366(83.2 \%)$ patients defined as all ITT subjects who took at least 6 doses of the study drug, with evidence of an attempt at intercourse reported following each dose [62].

Results showed greater mean per-subject percentages of successful intercourse attempts during the treatment period occurring within approximately 15 minutes of dosing for both avanafil 100mg (mean, 25.9\%, least squares [LS] mean [SE], 24.7\% [2.9]) and avanafil 200mg doses (mean, 29.1\%, LS mean [SE], 28.2\% [2.9]) compared to placebo (mean, 14.9\%, LS mean [SE], 13.8\% [2.9], $\mathrm{p}=0.002$ and $\mathrm{p}<0.001$, respectively [ANCOVA]; $\mathrm{p}=0.001$ and $\mathrm{p}<0.001$ [rank ANCOVA] [62]. Moreover, by the end of the study, the average per subject proportion of successful SEP3 responses 
was significantly greater at 12 and 10 minutes after dosing with the $100 \mathrm{mg}$ and the $200 \mathrm{mg}$, respectively ( $\mathrm{p}<0.05$ vs. placebo). After 8 weeks of treatment, significant improvements were observed in SEP3, SEP2, and IIEF-EF scores for patients using avanafil compared to those taking the placebo ( $\mathrm{p}<0.001$ vs. placebo) [62] (Table 3). Corona et al. [58] also confirmed that avanafil had a rapid onset of action, leading to a 4-fold increased likelihood of successful intercourse within 15 minutes. Taken together, these findings highlight the clinical relevance of avanafil's rapid onset of action: the early absorption of avanafil (with peak concentrations reached approximately 30 minutes from intake) may translate into a $50 \%$ reduction in the standard wait time of 30 minutes to achieve an erection adequate for successful sexual intercourse. The fact that patients reached this state within 15 minutes post dosing with avanafil and the sustained duration of the erectogenic effect highlight the drug's ability to support sexual naturalness and spontaneity for both patients and their partners $[34,63,64]$. Avanafil $200 \mathrm{mg}$ emerged to promote an early onset of action in the largest group of patients.

\subsection{Dosage and Administration - Practical considerations in the everyday clinical setting}

The recommended starting dose for avanafil is $100 \mathrm{mg}$ per os as needed before sexual activity, with or without food intake $[32,52]$. In the everyday clinical setting we usually advise patients to take the same compound at the same dose for no fewer than six consecutive sexual attempts before deciding that the drug or the dose are not appropriate for him based on efficacy or possible side effects. However, overall data and the real-life clinical experience of these authors suggest that avanafil 200mg promotes better results with a comparable safety profile [58]. Therefore, the dose is often immediately uptitrated to $200 \mathrm{mg}$ to achieve greater effectiveness, without a consequent increase of TEAEs. Conversely, avanafil can be downtitrated to a $50 \mathrm{mg}$ dose when required to promote efficacy and tolerability [32,54]. The maximum recommended dose frequency is once per day, 15 to 30 minutes prior to sexual activity [50]. Dose adjustment is not required for men $\geq 65$ years; however, there are limited data on the use of avanafil in men $\geq 70$ years old. 
As stated, administration with fatty food may delay the onset of clinical effects compared with administration in a fasting state. In any case, sexual stimulation is required in order for avanafil to be effective.

The efficacy of avanafil may persist for at least 6 hours post dosing. Patients with mild or moderate renal impairment, patients with diabetes or with mild or moderate hepatic impairment should initiate treatment with the minimum effective dose $(50 \mathrm{mg})$, which may be subsequently adjusted as needed according to tolerability. Avanafil is contraindicated in patients with severe renal or hepatic impairment $[32,49,50,54]$.

Although avanafil is indicated for the treatment of ED in adult men, it has not yet been evaluated in patients with ED due to spinal cord injury or other neurological disorders. The effects of avanafil on heart rate and blood pressure appear to be less consequential than those of the other PDE5Is [51]. Nevertheless, according to more recent recommendations [65], avanafil should not be indicated for men with pre-existing cardiovascular disease, including previous myocardial infarction, stroke or life-threatening arrhythmias, resting hypo-or hypertension, unstable angina, angina with sexual intercourse or congestive heart failure. For this specific reason, the cardiac risk of sexual activity should be considered in patients with pre-existing cardiovascular disease before prescribing avanafil [65]. Moreover, as previously stated, avanafil is not indicated in patients under treatment with organic nitrates or nitric oxide donors, due to the high risk of hypotension, especially if both are administered within 12 hours [50].

Though no syncope or serious adverse events were reported, men taking alpha1-blockers prior to starting treatment with avanafil should be on a stable dose of alpha1-blocker therapy and should initiate treatment at the lowest avanafil dose of 50mg. Conversely, patients already receiving an optimised dose of avanafil should start alpha1-blocker therapy at the lowest dose. The use of additional anti-hypertensives may affect the safety of the avanafil/alpha-blocker combination.

Moreover, avanafil is contraindicated in patients with loss of vision in one eye due to non-arteritic, anterior, ischaemic optic neuropathy. Nevertheless, the current literature suggests that avanafil is a 
safe and effective oral treatment for patients who experience visual disturbances with the other agents [66]. Avanafil is not indicated in patients with hypersensitivity to the drug or any of the excipients. Avanafil is not indicated in women.

\section{Safety and tolerability}

Overall, the prevalence of AEs for avanafil is similar, if not lower, to that of other PDE5Is [17], and when AEs do occur they are generally mild in nature [2,41,53] (Table 4). No differences between avanafil $100 \mathrm{mg}$ and $200 \mathrm{mg}$ and placebo were observed for the incidence of severe AEs [58]. Moreover, both avanafil 100 and $200 \mathrm{mg}$ had a discontinuation rate similar to placebo due to AEs [58]. Largely based on phase III clinical trials, the most frequently reported post-dosing TEAEs, occurring in at least $2 \%$ of treated patients (all doses included), were headache $(2.7 \%$ to $12.1 \%$ ), flushing ( $1.4 \%$ to $13 \%)$, nasopharynigitis $(0.6 \%$ to $5.1 \%)$, nasal congestion $(0.6 \%$ to $4.3 \%)$, and back pain $(0.6 \%$ to $3 \%)$ [50,53,54]. Although direct head-to-head comparison studies among the different PDE5Is are not currently available, it seems of clinical importance that avanafil 200mg showed the lowest rate of common AEs in terms of headache $(9.3 \%$ vs. sildenafil $100 \mathrm{mg} 12.8 \%$ vs. tadalafil $20 \mathrm{mg} 14.5 \%$, and vs, vardenafil $20 \mathrm{mg} 16 \%$ ) and flushing (3.7\% vs. sildenafil 100mg $10.4 \%$ vs. tadalafil $20 \mathrm{mg} 4.1 \%$ and vardenafil $20 \mathrm{mg} 12 \%$ ) compared to the other PDE5Is [2] (Table 4). Moreover, recent network meta-analysis on placebo-controlled RCTs have reported that avanafil has the lowest incidence of AEs compared to the other currently-available PDE5Is when the drugs are prescribed at the maximum dosage [57,58]. Infrequently occurring AEs were dyspepsia, dizziness, fatigue and upper respiratory infections; only one patient reported a visual colour disturbance in the open label extension trial, while priapism or hearing loss were not experienced during the clinical trials $[53,54]$. No clinically relevant effects were noted on vital signs, laboratory parameters, or electrocardiograms. Overall, the incidence of AEs was dose-dependent, with individuals with a BMI $<25 \mathrm{~kg} / \mathrm{m} 2$ reporting AEs most frequently $[32,49]$. Interestingly, avanafil 200mg did not differ from the 100mg dose in terms of TEAEs when considering either patients with 
only ED or individuals with both ED and diabetes mellitus [52,53,58].

Overall, less than $3 \%$ of patients discontinued therapy due to adverse events [53,54].

The safety profile of avanafil, shown along its clinical development, was also confirmed in a phase IV study (TA-501) which was conducted to evaluate the therapeutic effects of avanafil approximately 15 minutes after dosing in men with mild to severe ED [62]. Although comparing TEAEs between doses may be misleading, as all of the trials of avanafil used dose titration where men were likely to increase to $200 \mathrm{mg}$ only if they tolerated $100 \mathrm{mg}$, the overall incidence of AEs was similar in the placebo group and the avanafil $100 \mathrm{mg}$ group $(21.0 \%$ and $20.5 \%$, respectively), but slightly higher in the avanafil 200mg group (27.4\%) [62].

As previously mentioned, a distinct characteristic of avanafil is its high selectivity to the PDE5 isoenzyme, which translates to a good safety and tolerability profile. From a clinical perspective this feature acquires more importance in the setting of possible administration to specific populations of patients. Doses may be administered with on without food, although fatty foods may affect absorption [32]. Moreover, avanafil was generally well tolerated throughout the clinical trials, as AEs were mainly mild to moderate. Belkoff et al. [55] showed that only $0.4 \%$ of patients requested that the initial avanafil dose be decreased due to poor tolerability, with only $2.8 \%$ discontinuation due to AEs. 


\section{Conclusions}

Avanafil is a $2^{\text {nd }}$-generation, highly selective and potent PDE5I that was recently approved and launched on the market, almost worldwide. Avanafil has demonstrated comparable efficacy to the currently available oral PDE5Is, both in naïve and in previous PDE5I users. Avanafil has been demonstrated to be most effective at the $200 \mathrm{mg}$ dose, and works well even in difficult-to-treat populations such as diabetic men and patients who have undergone major oncological pelvic surgery, although larger studies with high volume cohorts are still missing for this specific oral treatment.

Avanafil has been documented to be efficacious within approximately 15 minutes of dosing in most patients. Moreover, avanafil remains effective for at least 6 hours and may maintain drug-related benefits longer in some patients. Taken together, these features may promote greater sexual spontaneity and naturalness both for the patient and their partners in the real-life setting. Available data have shown that of all PDE5Is avanafil has the greatest selectivity for the PDE5 isoenzyme, thus resulting in very few AEs typical of this drug class, including hemodynamic side effects. Overall, avanafil has been shown to be well tolerated even at the highest dose, with AEs of mild to moderate intensity, making the molecule extremely adequate for proper on-demand personalized treatment of patients in the daily clinical practice. 


\section{Expert commentary}

Several studies have investigated the clinical efficacy, safety and tolerability of the currently available PDE5Is (sildenafil, vardenafil, tadalafil) for the treatment of ED. However, high levels of treatment dissatisfaction have been reported among ED patients. The primary reasons associated with treatment discontinuation are ED severity, TEAEs, treatment-related lack of sexual spontaneity, relational or interpersonal factors and costs. Moreover, the treatment of ED in couples must not be limited to the restoration of erectile functioning, but should aim to enable both partners to enjoy a satisfactory sexual experience. Patient preference for specific PDE5Is, based on their unique characteristics, must clearly be considered. Avanafil is a potent, highly selective PDE5I with the potential to be the proper on-demand treatment for ED patients. Avanafil's efficacy is comparable to that of currently available oral PDE5Is in both naïve and previous PDE5I users. Avanafil is effective within approximately 15 minutes of dosing. Moreover, Avanafil remains effective for at least 6 hours and may maintain drug-related benefits longer in some patients. Taken together, these features provide an adequate combination of speedy and lasting effectiveness, allowing for a more natural sexual spontaneity for both patients and their partners in the real-life setting. Avanafil has high selectivity for the PDE5 isoenzyme, thus resulting in very few AEs. Overall, avanafil's molecular characteristics make it a good choice for proper on-demand patienttreatment tailoring in the daily clinical practice, with the dose of $200 \mathrm{mg}$ able to promote the best balance between high effectiveness and tolerability. 


\section{Five-year view}

Oral PDE5Is have revolutionised the treatment of ED due to their desirable combination of efficacy and tolerability. However, PDE5Is for ED are still ineffective in nearly $30 \%$ of patients. At present, the different pharmacological characteristics of each medication may make certain options more desirable to certain patients and should be carefully evaluated in order to properly tailor patient treatments. Because ED prevalence increases with age, future PDE5Is should also be effective in difficult to treat populations (e.g diabetic men and patients who have undergone major oncological pelvic surgery). Moreover, as these medications depend on sexual stimulation and intact NO signalling, current research is underway to develop medications that provide erections through NOindependent mechanisms.

\section{Key issues}

- Erectile dysfunction (ED) is defined as the persistent inability to attain and maintain an erection sufficient to permit satisfactory sexual performance.

- ED has a detrimental impact on quality of life and psychological health, due to both its prevalence and its effects on individual patients and their partners.

- Phosphodiesterase type 5 inhibitors (PDE5Is) have demonstrated efficacy and safety for the treatment of ED, and are considered the first-line treatment.

Almost one in two patients show some level of treatment dissatisfaction and up to $30 \%$ of ED patients fail to respond to any of the currently available PDE5Is.

- The optimal ED treatment should be chosen among the currently available PDE5Is according to PDE selectivity, a favourable pharmacokinetic profile, efficacy and safety to 
address patient and partner satisfaction.

- Avanafil is a recently-approved second-generation, potent and highly selective PDE5I.

- Avanafil is effective within 15 minutes of dosing, remains effective for at least 6 hours and may maintain drug-related benefits longer in some patients. These features provide an adequate combination of quick and lasting effectiveness, allowing for a more natural sexual spontaneity for both patients and their partners in the real-life setting.

- Avanafil has high selectivity for the PDE5 isoenzyme, thus resulting in very few AEs. Overall, avanafil's molecular characteristics make it an adequate choice for proper ondemand patient-treatment tailoring in the daily clinical practice, with the dose of $200 \mathrm{mg}$ able to promote the best balance between high effectiveness and tolerability.

\section{Declaration of Interest}

This study was supported by a contribution from A. Menarini Farmaceutica Internazionale. The authors have no other relevant affiliations or financial involvement with any organization or entity with a financial interest in or financial conflict with the subject matter or materials discussed in the manuscript apart from those disclosed. No writing assistance was utilized in the production of this manuscript.

\section{Acknowledgements}

The authors thank Dana Kuefner $\mathrm{PhD}$ for reviewing the language in this manuscript. 


\section{REFERENCES}

1. NIH Consensus Development Panel on Impotence. JAMA 1993; 270:83-90.

2. **Hatzimouratidis K, Eardley I, Giuliano F et al. European Association of Urology. Guidelines on male sexual dysfunction: erectile dysfunction and premature ejaculation. 2015. http://uroweb.org/wp-content/uploads/EAU-Guidelines-Male-Sexual-Dysfunction-2015-v2.pdf.

Produced the first EAU guidelines on male sexual dysfunction containing the PDE5I avanafil as a treatment option for ED.

3. McCabe MP, Sharlip ID, Lewis R et al. Incidence and Prevalence of Sexual Dysfunction in Women and Men: A Consensus Statement from the Fourth International Consultation on Sexual Medicine 2015. J Sex Med. 2016; 13:144-52.

4. Capogrosso P, Colicchia M, Ventimiglia E et al. One patient out of four with newly diagnosed erectile dysfunction is a young man - worrisome picture from the everyday clinical practice. $J$ Sex Med 2013; 10:1833-1841.

5. Jannini EA, Sternbach N, Limoncin E et al. Health-related characteristics and unmet needs of men with erectile dysfunction: a survey in five European countries. J Sex Med 2014; 11:40-50.

6. Porst H, Burnett A. Brock G et al. ISSM Standards Committee for Sexual Medicine. SOP conservative (medical and mechanical) treatment of erectile dysfunction. J Sex Med 2013; 10:130171.

7. Gupta BP, Murad MH, Clifton MM et al. The effect of lifestyle modification and cardiovascular risk factor reduction on erectile dysfunction: a systematic review and meta-analysis. Arch Intern Med 2011; 171:1797-803.

8. Corona G, Isidori AM, Aversa A et al. Endocrinologic Control of Men's Sexual Desire and Arousal/Erection. J Sex Med 2016; 13:317-37. 
9. Isidori AM, Balercia G, Calogero AE et al. Outcomes of androgen replacement therapy in adult male hypogonadism: recommendations from the Italian society of endocrinology. $J$ Endocrinol Invest 2015; 38:103-12.

10. Goldstein I, Lue TF, Padma-Nathan H et al. Sildenafil Study Group. Oral sildenafil in the treatment of erectile dysfunction. 1998. J Urol 2002; 167:1197-1203.

11. Salonia A, Rigatti P, Montorsi F. Sildenafil in erectile dysfunction: a critical review. Curr Med Res Opin 2003; 19:241-262.

12. Brock GB, McMahon CG, Chen KK et al. Efficacy and safety of tadalafil for the treatment of erectile dysfunction: results of integrated analyses. J Urol 2002; 168:1332-1336.

13. Porst H, Padma-Nathan H, Giuliano F et al. Efficacy of tadalafil for the treatment of erectile dysfunction at 24 and 36 hours after dosing: a randomized controlled trial. Urology 2003; 62:121125.

14. Sanford M. Vardenafil orodispersible tablet. Drugs 2012; 72:87-98.

15. **Yuan J, Zhang $\mathrm{R}$, Yang $\mathrm{Z}$ et al. Comparative effectiveness and safety of oral phosphodiesterase type 5 inhibitors for erectile dysfunction: a systematic review and network metaanalysis. Eur Urol 2013; 63:902-12.

Performed a systemic review and network meta-analysis investigating the comparative effects as well as the efficacy and safety of different classes of oral PDE5-Is for ED.

16. McMahon CN, Smith CJ \& Shabsigh R. Treating erectile dysfunction when PDE5 inhibitors fail. BMJ 2006; 332: 589-592.

17. Smith WB 2nd, McCaslin IR, Gokce A et al. PDE5 inhibitors: considerations for preference and long-term adherence. Int J Clin Pract 2013; 67:768-780. 
18. Salonia A, Gallina A, Zanni $G$ et al. Acceptance of and discontinuation rate from erectile dysfunction oral treatment in patients following bilateral nerve-sparing radical prostatectomy. Eur Urol 2008; 53: 564-570.

19. Corona G, Mondaini N, Ungar A et al. Phosphodiesterase type 5 (PDE5) inhibitors in erectile dysfunction: the proper drug for the proper patient. J Sex Med 2011; 8:3418-3432.

20. *Carvalheira AA, Pereira NM, Maroco J et al. Dropout in the treatment of erectile dysfunction with PDE5: a study on predictors and a qualitative analysis of reasons for discontinuation. $J$ Sex Med 2012; 9:2361-2369.

\section{Investigated the reason for PDE5I treatment discontinuation in ED patients.}

21. Scranton RE, Goldstein I, Stecher VJ. Erectile dysfunction diagnosis and treatment as a means to improve medication adherence and optimize comorbidity management. J Sex Med 2013; 10:551561.

22. Chrysant SG. Effectiveness and safety of phosphodiesterase 5 inhibitors in patients with cardiovascular disease and hypertension. Curr Hypertens Rep 2013; 15:475-483.

23. Alberti L, Torlasco C, Lauretta L et al. Erectile dysfunction in heart failure patients: a critical reappraisal. Andrology 2013; 1:177-191.

24. Gur S, Kadowitz PJ, Gokce A et al. Update on drug interactions with phosphodiesterase-5 inhibitors prescribed as first-line therapy for patients with erectile dysfunction or pulmonary hypertension. Curr Drug Metab 2013; 14:265-269.

25. Buvat J, Büttner H, Hatzimouratidis $\mathrm{K}$ et al. Adherence to initial PDE-5 inhibitor treatment: randomized open-label study comparing tadalafil once a day, tadalafil on demand, and sildenafil on demand in patients with erectile dysfunction. $J$ Sex Med 2013; 10:1592-1602. 
26. Hackett G, Kell P, Ralph D et al. British Society for Sexual Medicine. British Society for Sexual Medicine guidelines on the management of erectile dysfunction. J Sex Med 2008; 5:184165.

27. Hanson-Divers C, Jackson SE, Lue TF et al. Health outcomes variables important to patients in the treatment of erectile dysfunction. J Urol 1998; 159:1541-7.

28. Axilrod AC. Phosphodiesterase type 5 inhibitor therapy: identifying and exploring what attributes matter more to clinicians and patients in the management of erectile dysfunction. Curr Med Res Opin 2007; 23:3189-98.

29. Martin-Morales A, Gutiérrez-Hernández P, Romero-Otero J et al. Vadeopen Study Group. Duration of erection: does it really matter? A randomized, double-blind clinical trial to assess the impact of vardenafil ODT on duration of erection and its correlation with patients' and partners' sexual quality of life and duration of intercourse: the VADEOPEN study. J Sex Med 2014; 11:152738.

30.

http://www.menarini.com/Home/Therapy-and-Wellness/Search-the-TherapeuticAreas? avtSearch=spedra\&sb-inst $=3879 \&$ sb-logid=25338-ct141grm0soa8ezq $\quad\left(\right.$ accessed, Jan, $6^{\text {th }}$, 2015).

31. Vivus, Inc. Vivus announces FDA approval of STENDRA TM (avanafil) tablets for the treatment of erectile dysfunction [media release]. 2012. http://www.vivus.com.

32. **European Medicines Agency. Spedra (avanafil) 50, 100, 200 mg tablets: summary of product characteristics. http://www.ema.europa.eu/docs/en_GB/document_library/EPAR_Product_Information/human/002581/WC500145206.pdf (accessed Jan, $6^{\text {th }}, 2015$ ).

\section{Gives a summary of the product characteristics.}

33. Sanford M. Avanafil: a review of its use in patients with erectile dysfunction. Drugs Aging $2013 ; 30: 853-862$. 
34. Kedia GT, Uckert S, Assadi-Pour F et al. Avanafil for the treatment of erectile dysfunction: initial data and clinical key properties. Ther Adv Urol 2013; 5:35-41.

35. Gratzke C, Angulo J, Chitaley K et al. Anatomy, physiology, and pathophysiology of erectile dysfunction. J Sex Med 2010; 7:445-75.

36. Burnett AL. The role of nitric oxide in erectile dysfunction: implications for medical therapy. $J$ Clin Hypertens (Greenwich) 2006; 8:53-62.

37. Lue TF. Erectile dysfunction. N Engl J Med 2000; 342:1802-1813.

38. Sakamoto T, Koga Y, Hikota M et al. The discovery of avanafil for the treatment of erectile dysfunction: A novel pyrimidine-5-carboxamide derivative as a potent and highly selective phosphodiesterase 5 inhibitor. Bioorg Med Chem Lett 2014; 24:5460-5465.

39. Corbin JD, Francis SH. Pharmacology of phosphodiesterase-5 inhibitors. Int J Clin Pract 2002; $56: 453-459$.

40. Seftel AD. Phosphodiesterase type 5 inhibitors: molecular pharmacology and interactions with other phosphodiesterases. Curr Pharm Des 2005; 11:4047-4058.

41. Wang R, Burnett AL, Heller WH et al. Selectivity of avanafil, a PDE5 inhibitor for the treatment of erectile dysfunction: implications for clinical safety and improved tolerability. J Sex Med 2012; 9:2122-9.

42. Mehrotra N, Gupta M, Kovar A et al. The role of pharmacokinetics and pharmacodynamics in phosphodiesterase-5 inhibitor therapy. Int J Impot Res 2007; 19:253-264.

43. Limin M, Johnsen N, Hellstrom WJ. Avanafil, a new rapid-onset phosphodiesterase 5 inhibitor for the treatment of erectile dysfunction. Expert Opin Investig Drugs 2010; 19:1427-37.

44. Azzouni F, Abu Samra K. Are phosphodiesterase type 5 inhibitors associated with visionthreatening adverse events? A critical analysis and review of the literature. J Sex Med 2011; 8:2894903. 
45. Mochida H, Yano K, Inoue $\mathrm{H}$ et al. Avanafil, a highly selective phosphodiesterase type 5 inhibitor for erectile dysfunction, shows good safety profiles for retinal function and hemodynamics in anesthetized dogs. J Urol 2013; 190:799-806.

46. Lowe G \& Costabile RA. 10-Year analysis of adverse event reports to the Food and Drug Administration for phosphodiesterase type-5 inhibitors. J Sex Med 2012; 9:265-70.

47. Porst H, Gacci M, Büttner $\mathrm{H}$ et al. Tadalafil once daily in men with erectile dysfunction: an integrated analysis of data obtained from 1913 patients from six randomized, double-blind, placebocontrolled, clinical studies. Eur Urol 2014; 65:455-64.

48. Allison M, Grant T, Obaidi M et al. Pharmacokinetics of avanafil; a novel, rapidly-absorbed, selective PDE5 inhibitor for the treatment of mild to severe erectile dysfunction (ED) (abstract). $J$ Sex Med 2011; 8(Supplement 5): 466-7.

49. Vivus, Inc. STENDRA TM (avanafil) tablets: US prescribing information [online]. 2012. http://www.avanafil.com/assets/pdf/ STENDRA-avanafil-tablets-full-PI.pdf

50. *Katz EG, Tan RB, Rittenberg D et al. Avanafil for erectile dysfunction in elderly and younger adults: differential pharmacology and clinical utility. Ther Clin Risk Manag 2014; 10:701-11.

\section{Reported the pharmacology and the clinical utility of avanafil}

51. Swearingen D, Nehra A, Morelos S et al. Hemodynamic effect of avanafil and glyceryl trinitrate coadministration. Drugs Context 2013; 2013:212248.

52. *Goldstein I, McCullough AR, Jones LA et al. A randomized, double-blind, placebo-controlled evaluation of the safety and efficacy of avanafil in subjects with erectile dysfunction. $J$ Sex Med 2012; 9:1122-1133.

53. *Goldstein I, Jones LA, Belkoff LH et al. Avanafil for the treatment of erectile dysfunction: a multicentre, randomized double-blind study in men with diabetes mellitus. Mayo Clin Proc 2012; $87: 843-852$. 
54. *Belkoff LH, McCullough A, Goldstein I et al. An open-label, long-term evaluation of the safety, efficacy and tolerability of avanafil in male patients with mild to severe erectile dysfunction. Int J Clin Pract 2013; 67:333-341.

55. *Mulhall JP, Burnett AL, Wang R et al. A phase 3, placebo controlled study of the safety and efficacy of avanafil for the treatment of erectile dysfunction after nerve sparing radical prostatectomy. J Urol 2013; 189:2229-2236.

These three papers performed clinical trials evaluating efficacy, safety and tolerability of avanafil in different clinical settings (normal population and difficult to treat patients).

56. Zhao C, Kim SW, Yang DY, et al. Efficacy and safety of avanafil for treating erectile dysfunction: results of a multicentre, randomized, double-blind, placebo-controlled trial. BJU Int 2012; 110:1801-1806.

57. Chen L, Staubli SE, Schneider MP et al. Phosphodiesterase 5 inhibitors for the treatment of erectile dysfunction: a trade-off network meta-analysis. Eur Urol 2015; 68:674-80.

58. Corona G, Rastrelli G, Burri A et al. The safety and efficacy of Avanafil, a new 2(nd) generation PDE5i: comprehensive review and meta-analysis. Expert Opin Drug Saf 2016; 15:23747.

59. Rosen R, Broderick G, Shabsigh R et al. Sensitivity of the psychological and interpersonal relationship scales to oral therapies for erectile dysfunction. $J$ Sex Med 2005; 2:461-8.

60. Dean J, Hackett GI, Gentile V et al. Psychosocial outcomes and drug attributes affecting treatment choice in men receiving sildenafil citrate and tadalafil for the treatment of erectile dysfunction: results of a multicenter, randomized, open-label, crossover study. J Sex Med 2006; 3:650-61. 
61. Hellstrom WJ, Freier MT, Serefoglu EC et al. A phase II, single-blind, randomized, crossover evaluation of the safety and efficacy of avanafil using visual sexual stimulation in patients with mild to moderate erectile dysfunction. BJU Int 2013; 111:137-147.

62. **Hellstrom WJ, Kaminetsky J, Belkoff LH et al. Efficacy of avanafil 15 minutes after dosing in men with erectile dysfunction: a randomized, double-blind, placebo controlled study. Y Urol 2015; 194:485-492.

Conducted a multicentre randomized, double-blind, placebo-controlled phase-IV trial to assess the approximately 15 minutes post-dosing effect of either avanafil $100 \mathrm{mg}$ or $200 \mathrm{mg}$ taken as an on demand treatment for mild to severe ED.

63. Ückert S, Kuczyk MA, Oelke M. Phosphodiesterase inhibitors in clinical urology. Expert Rev Clin Pharmacol 2013;6:323-32.

64. Burri A, Porst H. Results from an online survey investigating ED patients' insights and treatment expectations. Int J Impot Res 2015;27:191-6.

65. Nehra A, Jackson G, Miner M et al. The Princeton III Consensus recommendations for the management of erectile dysfunction and cardiovascular disease. Mayo Clin Proc 2012; 87:766-78.

66. Evans JD, Hill SR. A comparison of the available phosphodiesterase-5 inhibitors in the treatment of erectile dysfunction: a focus on avanafil. Patient Prefer Adherence 2015; 9:1159-1164. 67. Sildenafil SPC. Sildenafil Summary of Product Characteristics. Available at:

http://www.emea.europa.eu/docs/en_GB/ document_library/EPAR_-_Product_Information/human/ 000202/WC500049830.pdf (accessed October 20, 2015).

68. Valiquette L, Montorsi F, Hellstrom WJ et al. Vardenafil Study Group. Penetration and maintenance of erection with vardenafil: a time-from-dosing analysis. Can J Urol. 2005;12:268798. 
Figure 1. A flow diagram of the study selec8on process.

Figure 1. A flow diagram of the study selection process.

75 articles were identified including:

MEDLINE: 68 articles

Google search: 7 articles

32 articles were excluded on the basis of the titles and the abstracts

43 relevant articles were included

On the basis of the low impact factor of the journal 8 articles were excluded

35 relevant articles were included

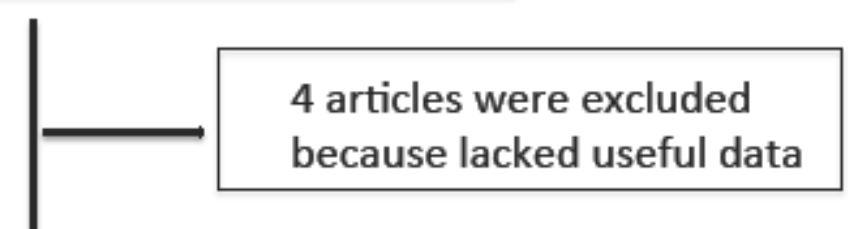

31 articles were gathered and examined including:

- Papers from reference lists of retrieved articles

- 5 RCTs (+ 1 open-label extension trial)

- 6 review articles

Abbreviations: RCT: randomized controlled trial. 
Table 1. Summary of pharmacokinetics of avanafil, sildenafil, vardenafil and tadalafil *

\begin{tabular}{|c|c|c|c|c|}
\hline Parameter & Avanafil & Sildenafil & Vardenafil & Tadalafil \\
\hline $\mathrm{T}_{\max }(\min )$ & $30-45$ & 60 & 60 & 120 \\
\hline Onset of action (min) & $15-30$ & 60 & $25-60$ & 30 \\
\hline Effect of food on $t_{\max }(\mathrm{hr})$ & Delayed by $1.25 \mathrm{~h}^{\#}$ & Delayed by $1 \mathrm{~h}$ & Delayed by $1 \mathrm{~h}^{\#}$ & None \\
\hline $\mathrm{T}_{1 / 2}(\mathrm{hr})$ & $6-17$ & $3-5$ & & 17.5 \\
\hline Duration of action (hr) & $>6^{* *}$ & $4-5^{\S}$ & $4-8^{\# \#}$ & 36 \\
\hline Metabolism & Hepatic (CYP3A4) & Hepatic (CYP3A4) & Hepatic (CYP3A4) & Hepatic (CYP3A4) \\
\hline Mode of excretion & $\begin{array}{l}\text { Feces }(63 \%) \text {, urine } \\
(21 \%)\end{array}$ & urine $(13 \%)$ & $\begin{array}{l}\text { Feces }(91 \%-95 \%) \text {, urine } \\
(2 \%-6 \%)\end{array}$ & Feces $(61 \%)$, urine $(36 \%)$ \\
\hline
\end{tabular}

Abbreviations: min, minutes; hr, hours; $\mathrm{T}_{1 / 2}$, time required for the concentration of the drug to reach half of its original value; $\mathrm{T}_{\max }$, time to maximum concentration; CYP, cytochrome P

* Data adapted from EMA statements on product characteristics

** after dosing in some subjects ${ }^{50}$

${ }^{\#}$ High fat meal

$\S$ as for Reference 67 
${ }^{\# \#}$ as for Reference 68

Table 2. Summary of pharmacokinetics of avanafil, sildenafil, vardenafil and tadalafil in special population*

\begin{tabular}{|c|c|c|c|c|}
\hline $\begin{array}{l}\text { Effect on exposure/clearance } \\
\text { of }\end{array}$ & Avanafil & Sildenafil & Vardenafil & Tadalafil \\
\hline Age & None & Reduced clearance & Reduced clearance & Reduced clearance \\
\hline Mild hepatic impairment & None & Increased exposure & Increased exposure & None \\
\hline Moderate hepatic impairment & Reduced exposure & Increased exposure & Increased exposure & None \\
\hline Severe hepatic impairment & Not studied & at & Not studied & Limited data \\
\hline Mild renal impairment & None & & None & Increased exposure \\
\hline Moderate renal impairment & None & & None & Increased exposure \\
\hline Severe renal impairment & No data & Increased exposure & Increased exposure & Increased exposure \\
\hline \multicolumn{5}{|l|}{ Drug interactions } \\
\hline CYP3A4 inhibitors & Increased exposure & Increased exposure & Increased exposure & Increased exposure \\
\hline Nitrates & $\begin{array}{l}\text { Potentiate hypotensive } \\
\text { effect - (Contraindicated) }\end{array}$ & $\begin{array}{l}\text { Potentiate hypotensive } \\
\text { effect - } \\
\text { (Contraindicated) }\end{array}$ & $\begin{array}{l}\text { Potentiate hypotensive } \\
\text { effect - (Contraindicated) }\end{array}$ & $\begin{array}{l}\text { Potentiate hypotensive effect } \\
\text {-(Contraindicated) }\end{array}$ \\
\hline
\end{tabular}




\begin{tabular}{llll}
$\begin{array}{l}\text { Alpha blockers } \\
\text { May lead to symptomatic } \\
\text { hypotension } \\
\text { (haemodynamic stability } \\
\text { and start PDE5I at lowest } \\
\text { dose) }\end{array}$ & $\begin{array}{l}\text { May lead to symptomatic } \\
\text { hypotension } \\
\text { (haemodynamic stability } \\
\text { and start PDE5I at 25mg } \\
\text { dose) }\end{array}$ & $\begin{array}{l}\text { May lead to symptomatic } \\
\text { hypotension } \\
\text { (haemodynamic stability } \\
\text { and start PDE5I at lowest } \\
\text { dose) }\end{array}$ & $\begin{array}{l}\text { May lead to symptomatic } \\
\text { hypotension (haemodynamic } \\
\text { stability and start PDE5I at } \\
\text { lowest dose). Association }\end{array}$ \\
\hline Acetyl salicylic acid & None & None & None
\end{tabular}

Definitions: mild renal impairment: estimated creatinine clearance $\geq 50 \mathrm{~mL} / \mathrm{min}$ but $<80 \mathrm{~mL} / \mathrm{min}$; moderate renal impairment: estimated creatinine clearance $\geq 30 \mathrm{~mL} / \mathrm{min}$ but $<50 \mathrm{~mL} / \mathrm{min}$; severe renal impairment: estimated creatinine clearance $<30 \mathrm{~mL} / \mathrm{min}$. Mild, moderate and severe hepatic impairment: Child-Pugh class A, B and C respectively.

* Data adapted from EMA statements on product characteristics and Reference 17 
Table 3. Summary of clinical trials

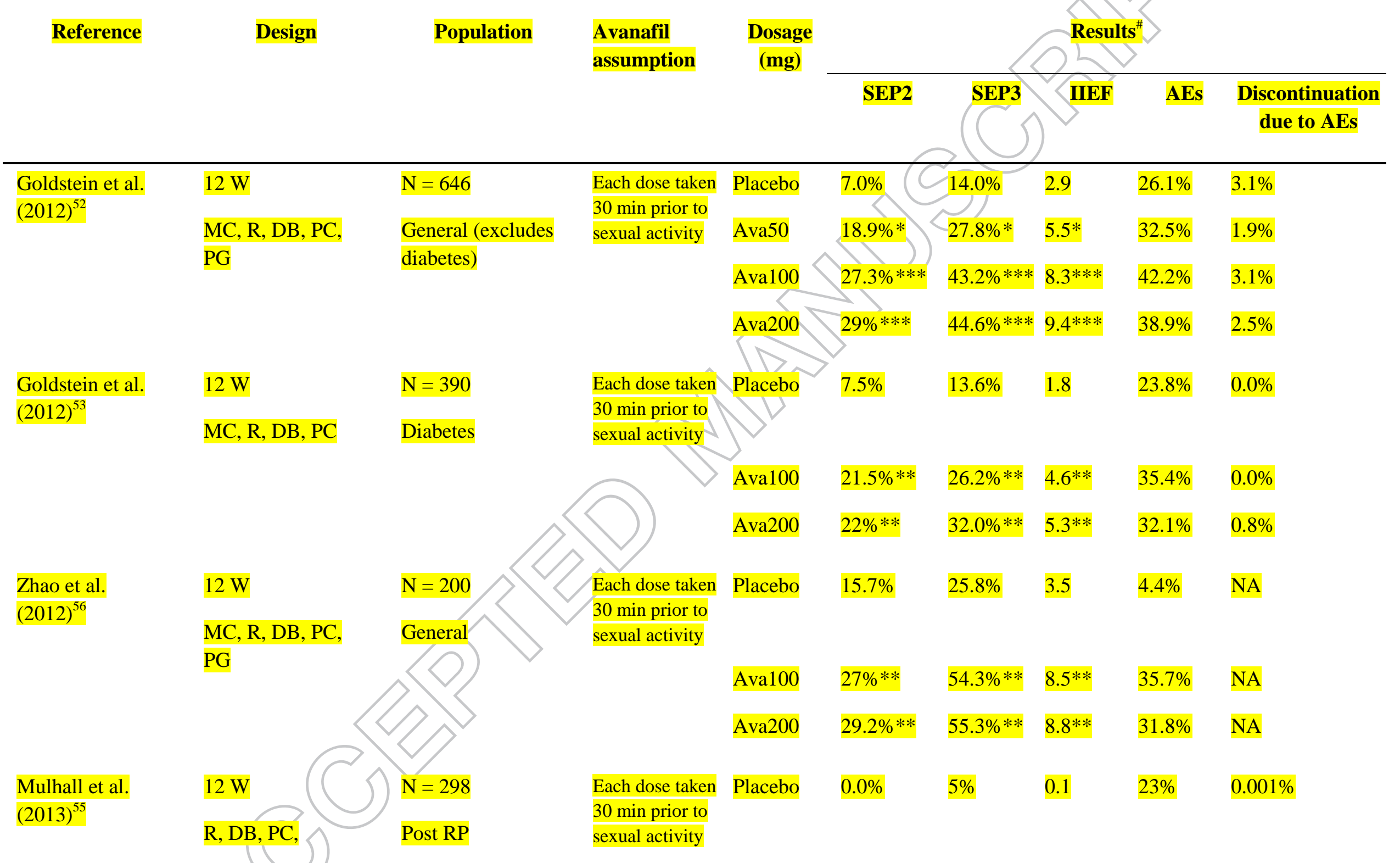




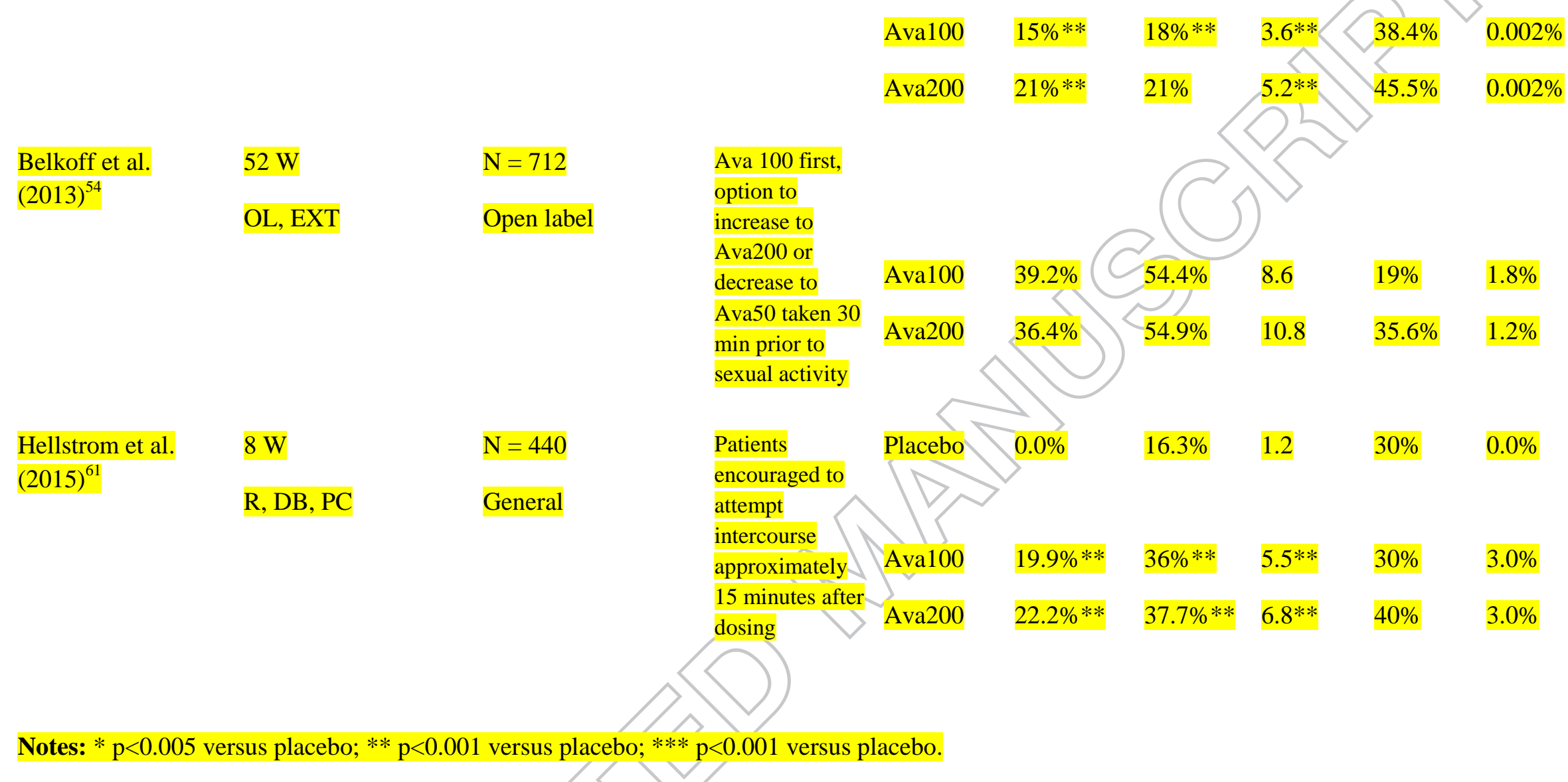

${ }^{\#}$ Values are changes of percentage of positive responses from baseline to end of treatment for SEP2 and SEP3. For IIEF values are changes of mean questionnaire score from baseline to end of treatment.

Abbreviations: W, week; MC, multicenter; $\mathrm{R}$, randomized; DB, double-blind; PC, placebo controlled; PG, parallel group; OL, open-label; EXT, extension; RP, radical prostatectomy; Ava50, avanafil $50 \mathrm{mg}$; Ava100, avanafil $100 \mathrm{mg}$; Ava200, avanafil $200 \mathrm{mg}$; min, minutes; SEP 2, Sexual Encounter Profile question 2 is "Were you able to insert your penis into your partner's vagina?"; SEP 3, Sexual Encounter Profile question 3 is “Did your erection last long enough for you to have successful intercourse?"; IIEF, International Index of Erectile Function. AEs, adverse events. 
Table 4. Common adverse events of the four PDE5 inhibitors approved by EMA for the treatment of erectile dysfunction *

\begin{tabular}{|c|c|c|c|c|}
\hline Adverse event & Avanafil $200 \mathrm{mg}$ & Sildenafil $100 \mathrm{mg}$ & Varde & Tadalafil $20 \mathrm{mg}$ \\
\hline Headache & $9.3 \%$ & $12.8 \%$ & $16 \%$ & $14.5 \%$ \\
\hline Flushing & $3.7 \%$ & $10.4 \%$ & & $4.1 \%$ \\
\hline Dyspepsia & Uncommon & $4.6 \%$ & & $12.3 \%$ \\
\hline Nasal congestion & $1.9 \%$ & $1.1 \%$ & & $4.3 \%$ \\
\hline Dizziness & $0.6 \%$ & $1.2 \%$ & $2 \%$ & $2.3 \%$ \\
\hline Abnormal vision & None & & $<2 \%$ & ------- \\
\hline Back pain & $<2 \%$ & & --- & $6.5 \%$ \\
\hline Myalgia & $<2 \%$ & & ------ & $5.7 \%$ \\
\hline
\end{tabular}

*Adapted from Hatzimouratidis K, Eardley I, Giuliano F, Moncada I, Salonia A; European Association of Urology. Guidelines on male sexual dysfunction: erectile dysfunction and premature ejaculation. 2015. http://uroweb.org/guideline/male-sexual-dysfunction/ 